\title{
Postoptimal Linear Programming ANALysis OF FARM MACHINERY
}

\author{
D. A. Bender, \\ Member \\ ASAE \\ D. E. Kline,
Assoc. Member \\ B. A. McCarl \\ ASAE
}

\begin{abstract}
Linear programming (LP) is a widely used technique for farm machinery selection. Shadow prices from LP models are typically used to identify farm machinery bottlenecks. Shadow prices represent the value of an additional unit of a scarce resource, such as planter hours during a given time period. This shadow price approach can be misleading since a machinery change may affect the usages of other scarce resources, such as tractors and labor.
\end{abstract}

A postoptimality algorithm is presented which improves on the shadow price approach. This algorithm gives detailed information on the effects of a machinery change on all relevant tractor and labor resources. This information is useful for investigating complex machinery interactions. The postoptimality algorithm is illustrated with a case study in Texas.

\section{INTRODUCTION}

$\mathrm{F}$ arm machinery for jobs such as planting, tilling, and harvesting directly or indirectly affect almost all farming activities. Any change to the machinery complement can affect overall system performance. For example, delays in tillage caused by undersized equipment can subsequently delay planting and harvesting operations. Such delays can substantially affect crop yields and farm profit. Furthermore, farm machinery resources involve large investments. Brown and Schoney (1985) indicate, for example, that machinery and building ownership costs accounted for approximately $25 \%$ of the total farm costs for wheat production systems. Other estimates of machineryrelated costs have been reported to be as high as $40 \%$ of the total cost for crop production (Chen, 1986). Therefore, the success of many farm-level production systems depends on wise selection of machinery systems.

Early studies of farm machinery selection involved static, economic budgeting. Hunt $(1963,1969)$ extended the mathematical treatment of the machinery selection problem to include dynamic variables. Some more recent approaches include simulation (e.g., Edwards and

Article has been reviewed and approved for publication by the Power and Machinery Div. of ASAE.

This article has been assigned Journal Paper No. TA-23747 by the Texas Agric. Expt. Station of Texas A\&M Univ.

The authors are D. A. Bender, Associate Professor, Agricultural Engineering Dept., Texas A\&M University, College Station; D. E. Kline, Assistant Professor, Dept. of Wood Science and Forest Production, Virginia Tech, Blacksburg; and B. A. McCarl, Professor, Agricultural Economics Dept., Texas A\&M University, College Station.
Boehlje, 1980; McClendon et al., 1987), linear programming (e.g., Krutz et al., 1980; McCarl et al., 1977; Whitson et al., 1981), mixed integer programming (e.g., Al-Soboh et al., 1986; Danok et al., 1978; 1980) or some combination of these techniques (e.g., Bender et al., 1984). Simulation is particularly good for modeling stochastic and dynamic responses, but it has been criticized for hidden, implicit assumptions and the difficulty of establishing system optimality. Linear programming is a powerful optimization technique for modeling complex systems. However, it is difficult to model transient and stochastic responses and the integer nature of machinery selection. Usually, machinery selection with LP is done through trial and error in determining what machinery to add using shadow prices as guidance (Doster et al., 1980). Mixed integer programming is better for matching machinery sets, but these models are computationally complex and not easily generalized. In addition, it is difficult to incorporate stochastic considerations in mixed integer models.

Linear programming has been a widely used line of attack in machinery selection due to its analytical power, computational tractability, and relatively few restrictive assumptions. Shadow prices are often used to identify limiting machinery resources in LP models. A shadow price is the marginal value of a limiting resource. For example, a shadow price of $\$ 200$ for the resource "planting time" indicates that another unit of the planting time resource is worth $\$ 200$. This increase in planting time resource could be obtained in two ways. First, the existing planting equipment could be operated more time per day. Second, larger planting equipment (or additional equipment) could be operated the same amount of time per day.

Several problems can arise when shadow prices are used to identify undersized field machinery. For example, shadow prices can be misleading when redundant constraints are present (McCarl, 1977). Furthermore, potential problems arise when the acquisition of a machinery resource changes the coefficients within a number of constraints (McCarl and Nuthall, 1982). For example, the acquisition of a larger rowcrop planter may change the planter, labor, and tractor usage over several time periods and crops, but the shadow price on planting time is only based on the planting time resource within a single time period. Thus, relevant shadow prices need to be aggregated to accurately reflect the marginal value of planting capacity.

\section{Objective}

The objective of this article is to present a postoptimality analysis procedure that can be 
incorporated into farm management linear programming models to evaluate the value of added field machinery capacity. This procedure is compared with a shadow price approach for a case study in Texas.

\section{Postoptimality APPROACH FOR MaChineRY VALUATION}

A shadow price reflects the objective function contribution per unit increment in a particular righthand side, provided the LP basis does not change. Righthand sides refer to resource endowments in LP models. A shadow price is determined for each constraint and is non-zero when the resource endowment has been fully utilized. A postoptimality approach is presented which offers an improved method of estimating the value of farm machinery changes by utilizing the shadow price information.

The LP problem can be presented in collapsed notation as

$$
\begin{array}{lc}
\text { Maximize } & \sum_{j} C_{j} X_{j} \\
\text { Subject to } & \sum_{j} a_{i j} X_{j} \leq b_{i} \\
& X_{j} \geq 0
\end{array}
$$

$$
\begin{aligned}
& \text { where } \\
& \mathrm{C}_{\mathrm{j}}=\text { profit contribution per unit of the } \mathrm{j}^{\mathrm{j}} \text { activity in } \\
& \text { the objective function, } \\
& a_{i j}=\text { technical coefficient for the } i^{\text {th }} \text { constraint and }
\end{aligned}
$$

Suppose that a change in machinery performance is considered. Such an alteration affects a set of $a_{i j}$ 's. Let this set be denoted by the subscripts $i^{*}$ and $j^{*}$, where $i^{*}$ are the rows in which at least one $a_{i j}$ changes and $j^{*}$ are the columns in which at least one $a_{i j}$ changes. Such an alteration would change resource usage, $\Delta \mathrm{r}_{\mathrm{i}^{*}}$, within the $\mathrm{i}^{* \text { th }}$ row by

$$
\Delta r_{i^{*}}=\sum_{j \in j^{*}}\left(a_{i^{*} j}^{n}-a_{i^{*} j}^{o}\right) X_{j}^{0}
$$

where

$$
\begin{aligned}
& a^{n}{ }_{i j}=\text { new } a_{i j} \text { 's after alteration, } \\
& a^{0}{ }^{i j}=\text { old } a_{i j} \text { 's before alteration, } \\
& \mathrm{X}^{\circ}{ }_{\mathrm{j}}=\text { optimal values of the } \mathrm{j}^{\text {th }} \text { decision variable in }
\end{aligned}
$$

This equation implies that the anticipated change in resource usage of the $i^{\text {th }}$ resource is the change in the $a_{i j}$ 's, $\left(a^{n}{ }_{i j}-a^{\circ}{ }_{i j}\right)$, times the level of usage, $X_{j}$, in the previous solution.

Equation 1 can be extended to generate an approximate shadow price relevant to an alteration in machinery. Consider a set of shadow prices, $\mathrm{U}_{\mathrm{i}^{*}}$, for the resources before the machinery is altered. The approximate change in the objective function from the change in machinery can be estimated by multiplying the change in resource usage, $\Delta \mathrm{r}_{\mathrm{i}^{*}}$, by the shadow prices, $\mathrm{U}_{\mathrm{i}^{*}}$, from the solution of the model before alterations. The change in the objective function, denoted VM, is expressed mathematically as

$$
V M=\sum_{i \in i^{*}} U_{i} \Delta r_{i}=\sum_{i \in i^{*}} \sum_{j \in j^{*}} U_{i}\left(a_{i j}^{n}-a_{i j}^{0}\right) X_{j}^{0}
$$

This formula was originally developed by Mills (1956) and its history is reviewed and Freund (1985). This procedure gives a way of investigating the likely economic effects of a change in machinery. The approach recognizes that a change in machinery simultaneously alters the usage of multiple resources, such as labor, tractors, and implements. The procedure involves valuing the total change in resources induced by a machinery change by considering all changes, multiplied by their shadow prices across all activities which use these resources. This contrasts with the traditional LP shadow price approach which identifies potential changes in machinery by examining the implement and/or tractor shadow prices in isolation.

The information resulting from equation 2 should be useful in machinery selection applications. However, this relationship gives the first derivative of the change in the objective function and is not exact since the optimal value of the basic $X_{j}$ 's after the change is determined by inversion of the basis matrix which contains the altered $a_{i j}$ 's. Later in this article, the accuracy of this approach is examined.

\section{IMPLEMENTATION OF Postoptimality APPROACH \\ Repfarm Linear Programming Model}

An existing LP model was used to implement the postoptimality analyzer. This model is called REPFARM (McCarl, 1982; McCarl and Pheasant, 1983). REPFARM determines optimal farm plans given information on time availability of machinery resources, yields, input usages, on-farm processing possibilities and crop rotations. REPFARM is designed to be flexible and is applicable to many agricultural environments. Versions of the model have been used in various locations, such as Indiana, Washington, and Texas. The model is useful in predicting the returns to investments in machinery and land, as well as the consequences of rotations, farm provisions, price environments, and technological changes.

The structure of REPFARM is shown in Fig. 1. Input data are entered in two phases: SETUP data and FARM data. The SETUP data define the general domain of the model, such as time periods, crops and their corresponding cultural practices and crop rotations. The SETUP data file is processed to generate a unique farm data input form. FARM data include detailed information such as fixed and variable costs, prices, machinery working rates, good field days availability, crop yields, and moisture contents for each possible combination of planting and harvest dates.

The next step shown in Fig. 1 is to convert the SETUP and FARM input data into a standard matrix form which can be passed to an LP solver. Basically, the SETUP data are used to define the model structure, such as the number of columns and rows in the LP matrix. 


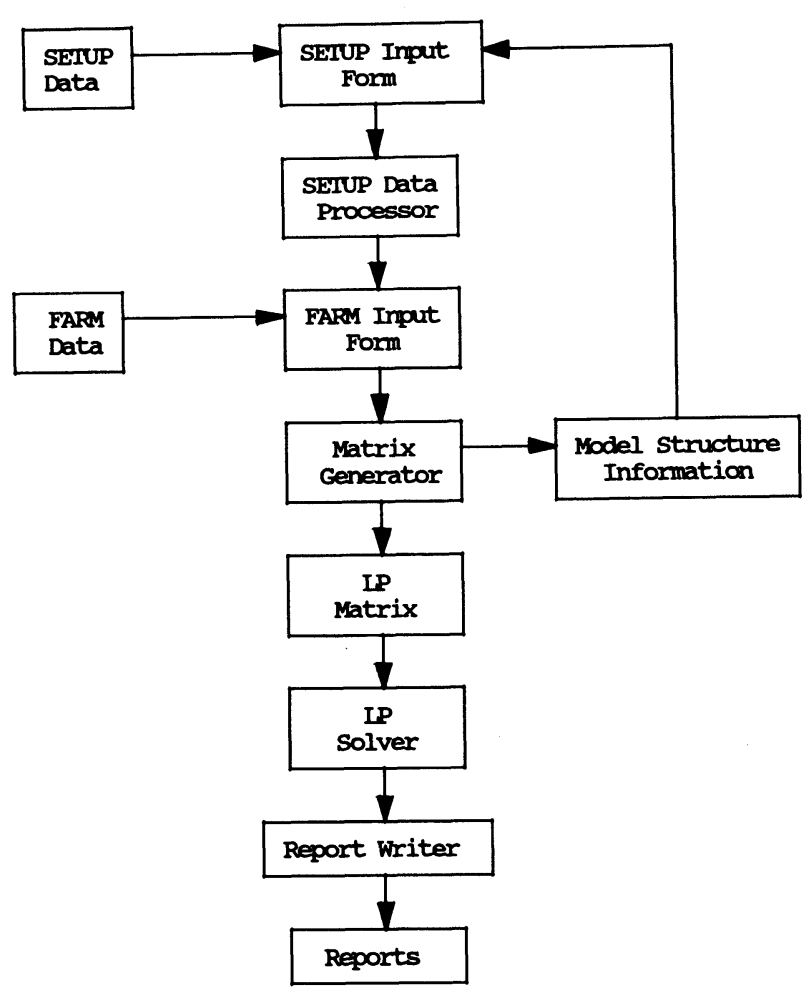

Figure 1-Structure of REPFARM linear programming system (McCarl, 1982).

The FARM input data are used to calculate the coefficients in the matrix. Error checking is also performed at this stage and default data are used to complete the data set. Two LP matrices are generated at this stage. The first is for a "present plan" in which the crop mix is fixed by the LP user. The present plan allows users to check the accuracy of their input data by comparing their current farm plan with the LP solution. The second LP matrix does not fix crop mix and the unrestricted optimal farm plan is solved.

After the matrices are defined, an LP solver is invoked. The LP solver is not formally part of the REPFARM system. A suitable solver must be available on the host computer. The MINOS (Murtagh and Saunders, 1983) optimizer is used in the research reported here. Procedures for interfacing REPFARM with other LP solvers are discussed by McCarl and Pheasant (1983).

The final software module shown in Fig. 1. is called the REPORT WRITER. REPORT WRITER reads the SETUP and FARM input data, along with the solutions from the LP solver and creates reports which summarize revenues, costs, field operation schedules, crop yields, production activities, and shadow prices.

\section{Postoptimality Analysis Module}

The research reported in this article required that an additional software module be added to the REPFARM system. This software module facilitates the LP postoptimality analyses outlined in equations 1 and 2 . This module accesses the LP solution, selected input data (from SETUP and FARMER data) and selected outputs from the REPORT WRITER. Then, the module outputs the corresponding values of VM (using equation
2 for a $1 \%$ increase in machinery working rates for each machinet. These values of VM are referred to as "machinery value indicators" throughout this manuscript. If machinery investment costs are known, the machinery value indicators could be modified to reflect the relative values of added machinery capacity. For example, the incremental value of a grain combine may be slightly larger than a planter; however, the purchase price of a combine is much greater than for a planter. Hence, the purchase of a larger planter would likely result in more profit.

The postoptimality analysis module also provides a detailed report on how the VM values are calculated by listing resource usages before and after the alterations in working rates for each implement. In this manner, the total value of a machinery change is related to the individual resources involved to identify a potential bottleneck. Features of the postoptimality module are illustrated in the following case study.

\section{Case Study}

For illustrative purposes, the postoptimality approach was implemented on the Texas A\&M University Plantation Farm. The Plantation Farm is located in the Brazos River Valley of Brazos County, Texas. The crop and livestock enterprises considered were cotton, hay, pasture, corn, soybeans, wheat, and Brangus beef cattle. The Plantation Farm target crop and livestock plan is shown in Table 1. Hay, pasture, and wheat for grazing were utilized solely for livestock feeding purposes. Crop yield, commodity price, input cost, and resource data for the Plantation Farm are presented in detail by Kline (1987). Due to the extensive nature of these data, only information relevant to farm machinery data will be presented in the case study.

The calendar of acceptable dates of machinery operations is presented for the Plantation Farm in Table 2. This table shows that the farming year was divided

†Machinery value indicators for tractors are calculated differently than for all other farm equipment in the REPFARM system. If tractor capacity is increased, it is difficult to identify all of the $a_{i j}$ 's that will change and to estimate the magnitude of the changes. This is due to the fact that field operations can be limited by speed or tractor power. For this reason, the machinery value indicators for tractors are set equal to the shadow prices.

TABLE 1. Plantation farm target plan

\begin{tabular}{lr}
\hline Crops & Hectares \\
Dryland Cotton & 127.0 \\
Irrigated Cotton & 71.2 \\
Hay & 11.7 \\
Pasture & 299.7 \\
Hay and Pasture & 33.7 \\
Corn Grain & 65.7 \\
Corn Silage & 56.7 \\
Soybeans & 33.5 \\
Wheat Grain & 58.9 \\
Wheat for Graze & 53.0 \\
& \\
Set Aside Land & 83.7 \\
& \\
Livestock & Head \\
Brangus & 34 \\
Cow-Calf & 224 \\
\hline
\end{tabular}


TABLE 2. Calendar of acceptable dates of machinery operations

\begin{tabular}{|c|c|c|c|c|c|c|c|c|c|c|c|c|c|}
\hline \multirow{2}{*}{$\frac{\text { Period }}{1}$} & Date & $\begin{array}{l}\text { Dryland } \\
\text { Cotton } \\
1234\end{array}$ & $\begin{array}{l}\text { Irrig. } \\
\text { Cotton } \\
1234\end{array}$ & 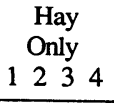 & \multirow[t]{2}{*}{$\begin{array}{l}\text { Hay and } \\
\text { Pasture } \\
1234\end{array}$} & $\begin{array}{l}\text { Corn } \\
\text { Grain } \\
1234\end{array}$ & $\begin{array}{c}\text { Corn } \\
\text { Silage } \\
1234 \\
\end{array}$ & $\begin{array}{l}\text { Soybeans } \\
1234\end{array}$ & \multicolumn{2}{|c|}{$\begin{array}{l}\text { Wheat } \\
\text { Grain } \\
1234\end{array}$} & \multicolumn{3}{|c|}{$\begin{array}{l}\text { Wheat } \\
\text { Graze } \\
1234 * \\
\end{array}$} \\
\hline & Dec 28 - Mar 1 & & & & & & & & & & & & \\
\hline 2 & Mar 2 - Mar 15 & 1 & 1 & & & & & & & & & & \\
\hline 3 & Mar 16-Apr 5 & 12 & 12 & & & 1 & 1 & 1 & & & & & \\
\hline 4 & Apr $6-$ Apr 19 & 12 & 12 & & & 12 & 12 & 12 & & & & & \\
\hline 5 & Apr 20 - May 3 & 12 & 12 & & & 12 & 12 & 12 & & & & & \\
\hline 6 & May 4-May 17 & 12 & 12 & 3 & & 2 & 2 & 2 & & 3 & & & \\
\hline 7 & May 18 - May 31 & 2 & 2 & & & & & & & 3 & & & \\
\hline 8 & Jun 1 - Jun 14 & & & & & & & 3 & & 3 & & & \\
\hline 9 & Jun 15 - Jun 28 & & & & & & & 3 & & & & & \\
\hline 10 & Jun 29 - Jul 12 & & & 3 & & & & 3 & & 4 & & & 4 \\
\hline 11 & Jul 13 - Jul 26 & & & & 3 & & 3 & & & 4 & & & 4 \\
\hline 12 & Jul 27 - Aug 9. & & & & & 3 & 3 & & 1 & 4 & 1 & & 4 \\
\hline 13 & Aug 10 - Aug 23 & 34 & 34 & & 3 & 34 & 34 & 4 & 1 & & 1 & & \\
\hline 14 & Aug 24 - Sep 6 & 34 & 34 & 3 & & 34 & 4 & 4 & 12 & & & 2 & \\
\hline 15 & Sep $7-\operatorname{Sep} 20$ & 34 & 34 & & & 4 & 4 & 4 & 2 & & & 2 & \\
\hline 16 & Sep 21 - Oct 18 & 34 & 34 & & & 4 & 4 & 4 & 2 & & & 2 & \\
\hline 17 & Oct 19 - Nov 22 & 34 & 34 & & & & & & & & & & \\
\hline 18 & Nov 23 - Dec 27 & 4 & 4 & & & & & & & & & & \\
\hline
\end{tabular}

* 1-Seedbed Preparation; 2-Plant; 3-Harvest; 4-Land Preparation.

into 18 time periods and the possible dates of machinery operation for each crop. Machinery operations were divided into four activity categories: 1) seedbed preparation activities, 2) planting activities, 3) harvesting activities, and 4) land preparation activities. The available machinery resources are listed in Table 3 with the assumed working rates. The small tractor resource pool consists of four tractors that are rated at less than $141 \mathrm{~kW}$ and the large tractor resource pool consists of one tractor that is rated at $141 \mathrm{~kW}$ or greater. Custom operations are hired for all harvesting activities except baling.

Net annual farm return above variable costs, added machinery investment cost, and farm machinery value indicators are compared in Table 4 for six different REPFARM runs. The first run shown in Table 4 is for the farm's Base Case. The other five runs represent the

TABLE 3. Machinery resources for the base case and working rate assumptions

\begin{tabular}{|c|c|c|c|}
\hline Description & $\begin{array}{l}\text { Tractor } \\
\text { used* }^{*}\end{array}$ & $\begin{array}{c}\text { Activity } \\
\text { type } \dagger\end{array}$ & $\begin{array}{l}\text { Rate } \\
\text { (ha/h) }\end{array}$ \\
\hline Bed Chopper & Small & 1 & 2.33 \\
\hline Disk \#1 & Big, Small & 1,4 & 1.88 \\
\hline$\# 2$ & Big & 1,4 & 1.88 \\
\hline Fertilizer Applicator & Small & 1 & 2.75 \\
\hline Ripper/Lister & Big & 1 & 4.17 \\
\hline Shredder & Small & 4 & 2.92 \\
\hline Subsoiler & Big & 4 & 4.17 \\
\hline Planter & Small & 2 & 1.72 \\
\hline Drill \#1 & Small & 2 & 2.75 \\
\hline \#2 & Small & 2 & 2.75 \\
\hline Baler & Small & 3 & 3.20 \\
\hline Custom Pick (cotton) & - & 3 & 1.60 \\
\hline Custom Combine (wheat) & - & 3 & 1.60 \\
\hline Custom Combine (Corn) & - & 3 & 1.60 \\
\hline Custom Combine (soybeans) & - & 3 & 2.00 \\
\hline Custom Chop (corn) & - & 3 & 3.20 \\
\hline \multicolumn{4}{|c|}{$\begin{array}{l}\text { * Four small tractors (less than } 141 \mathrm{~kW}) \text { and one large } \\
\text { tractor (141 kW or greater) were available. } \\
\begin{aligned}+ \text { Activity types included: } 1 \text { - seedbed preparation } \\
2 \text { - plant } \\
\\
3 \text { - harvest } \\
4 \text { - land preparation }\end{aligned}\end{array}$} \\
\hline
\end{tabular}

five machinery change cases that were studied: 1) double the number of large tractor resources, 2) double the disk working rate capacity, 3 ) double both the large tractor and disk capacity, 4) the large tractor, disk, and planter capacity. Each of the five machinery changes resulted in significantly increased annual return. Also, the increased returns exceeded the added annual investment costs for each of the machinery changes.

The machinery value indicators in Table 4 were obtained using the postoptimality approach. The machinery values indicate which of the farm resources were limiting farm productivity and profitability. Rather than making changes by trial and error, the machinery value indicators provided information on the appropriate machinery resources. For example, the machinery values for the Base Case run indicate that there are large tractor

TABLE 4. Comparison of annual return, added machinery cost, and farm machinery value indicators for each of the machinery change cases

\begin{tabular}{|c|c|c|c|c|c|c|}
\hline & $\begin{array}{l}\text { Base } \\
\text { Case }\end{array}$ & $\begin{array}{l}\text { Double } \\
\text { Tractor } \\
\text { Only } \\
\text { (Case 1) }\end{array}$ & $\begin{array}{l}\text { Double } \\
\text { Disk } \\
\text { Only } \\
\text { (Case 2) }\end{array}$ & $\begin{array}{l}\text { Double } \\
\text { Tractor } \\
\text { \& Disk } \\
\text { (Case 3) }\end{array}$ & $\begin{array}{c}\text { Double } \\
\text { Tractor } \\
\& \\
\text { Planter } \\
\text { (Case 4) }\end{array}$ & $\begin{array}{c}\text { Double } \\
\text { Tractor } \\
\text { Disk, \& } \\
\text { Planter } \\
\text { (Case 5) }\end{array}$ \\
\hline $\begin{array}{l}\text { Expected Annual } \\
\text { Return (\$) }\end{array}$ & 126694 & +158661 & 1158318 & 175752 & 163839 & 9185537 \\
\hline $\begin{array}{l}\text { Added Annual } \\
\text { Fixed Cost (\$) }\end{array}$ & 0 & 5392 & 3777 & 9169 & 7163 & 31094 \\
\hline $\begin{array}{l}\text { Machinery Value } \\
\text { Indicators*: }\end{array}$ & & & & & & \\
\hline $\begin{array}{l}\text { Small Tractors } \\
\text { Large Tractors }\end{array}$ & $\begin{array}{r}0 \\
670\end{array}$ & $\begin{array}{r}0 \\
137\end{array}$ & $\begin{array}{r}0 \\
1073\end{array}$ & $\begin{array}{l}0 \\
0\end{array}$ & $\begin{array}{r}0 \\
359\end{array}$ & $\begin{array}{l}0 \\
0\end{array}$ \\
\hline Bed Chopper & 0 & 26 & 0 & 72 & 10 & 66 \\
\hline Disk & 362 & 301 & 531 & 184 & 510 & 98 \\
\hline Fert. Applicator & 0 & 30 & 0 & 107 & 23 & 64 \\
\hline Ripper/Lister & 40 & 48 & 119 & 83 & 68 & 44 \\
\hline Shredder & 0 & 0 & 0 & 0 & & 0 \\
\hline Subsoiler & 0 & 0 & 0 & 0 & & 0 \\
\hline Planter & 0 & 238 & 0 & 193 & 31 & 51 \\
\hline Drill & 0 & 0 & 0 & 0 & & 0 \\
\hline Baler & 0 & 5 & 0 & 6 & & 4 \\
\hline
\end{tabular}

* The units for tractor machinery value indicators are $\$ / 1 \mathrm{~h}$ increase in tractor availability. The units for non-tractor machinery value indicators are $\$ / 1 \%$ increase in machinery working rate. 
TABLE 5. Shadow prices for each of the machine change cases

\begin{tabular}{|c|c|c|c|c|c|c|}
\hline & \multicolumn{6}{|c|}{ Farm Resource Shadow Price $(\$ / \mathrm{h})^{*}$} \\
\hline Farm Resource & $\begin{array}{l}\text { Base } \\
\text { Case }\end{array}$ & $\begin{array}{l}\text { Double } \\
\text { Tractor } \\
\text { Only } \\
\text { (Case 1) }\end{array}$ & $\begin{array}{l}\text { Double } \\
\text { Disk } \\
\text { Only } \\
\text { (Case 2) }\end{array}$ & $\begin{array}{l}\text { Double } \\
\text { Tractor } \\
\text { \& Disk } \\
\text { (Case 3) }\end{array}$ & $\begin{array}{c}\text { Double } \\
\text { Tractor } \\
\& \\
\text { Planter } \\
\text { (Case 4) }\end{array}$ & $\begin{array}{r}\text { Double } \\
\text { Tractor, } \\
\text { Disk, \& } \\
\text { Planter } \\
\text { (Case 5) }\end{array}$ \\
\hline Preparation Hours & 0 & 0 & 0 & 0 & 0 & 0 \\
\hline Planting Hours & 0 & 302 & 0 & 55 & 0 & 0 \\
\hline Harvesting Hours & 0 & 0 & 0 & 0 & 0 & 0 \\
\hline Small Tractor Hours & 0 & 0 & 0 & 0 & 0 & 0 \\
\hline Large Tractor Hours & 670 & 137 & 1073 & 0 & 359 & 0 \\
\hline Labor Hours & 0 & 149 & 0 & 280 & 97 & 150 \\
\hline
\end{tabular}

* The farm resource shadow prices are aggregated over all 18 time periods.

and disk resource limitations. Hence, another REPFARM analysis was conducted with increases in large tractor and disk resources.

After running REPFARM with doubled tractor capacity, the machinery values of Case 1 now indicate that the disk and planter are the major limiting machinery resources. Case 2 shows that doubling the disk capacity has nearly the same increase in annual farm returns as does doubling tractor capacity. Since the investment cost of a disk is significantly less than that of a tractor, doubling disk capacity is a better alternative. Because either the tractor, disk, or planter have relatively high values in Cases 1 and 2, changing just one machine does not adequately reduce the farm's machinery limitations. Therefore, Cases 3, 4, and 5 provide the results for simultaneously doubling two or more machines. In all cases, the machinery values in Table 4 indicate that the disk is limiting farm productivity.

Table 5 contains the shadow prices for each case. In contrast to the postoptimality approach, the shadow price approach to machinery selection does not provide any information that the disk is a limiting resource. Recall from Table 3 that the disk is used for land and seedbed preparation. Note that the shadow price for preparation hours is zero in all cases. The shadow price approach indicates that large tractor hours and planting hours are the only limiting machinery resources. Therefore, the shadow price approach does not always provide complete information as to which particular machinery resource should be changed.

The postoptimality approach also provides detailed information as shown in Table 6. As shown in the Base Case of Table 4, the value of a $1 \%$ increase in disk capacity is $\$ 362$. The total value of the disk change can be related to the individual resources involved for each time period. For example, the usage of large tractor resources in Period 3 was $70 \mathrm{~h}$ before the increase in disk capacity. By increasing the disk capacity by $1 \%$, the disk only required $69.3 \mathrm{~h}$ of the tractor resource to do the same amount of work. The savings of tractor hour resources in Period 3 is worth $\$ 149.60$.

Another advantage of the postoptimality approach is that it can quickly predict the value of a machinery change before re-executing the time-consuming REPFARM model. For example, the annual return predicted by the postoptimality approach is $\$ 144,953$ with doubled disk capacity. By re-running REPFARM with a doubled disk capacity, the annual return is
TABLE 6. Large tractor resource usages*

\begin{tabular}{|c|c|c|c|c|}
\hline Period & $\begin{array}{l}\text { Usage } \\
\text { Before }\end{array}$ & $\begin{array}{l}\text { Usage } \\
\text { After }\end{array}$ & $\begin{array}{c}\text { Shadow } \\
\text { Price }\end{array}$ & $\begin{array}{l}\text { Value of } \\
\text { Change }\end{array}$ \\
\hline & (h) & (h) & $(\$ / h)$ & $(\$)$ \\
\hline 3 & 70.00 & 69.38 & 239.90 & 149.60 \\
\hline 4 & 60.00 & 59.47 & 239.90 & 128.20 \\
\hline 5 & 50.00 & 49.55 & 171.20 & 76.20 \\
\hline 6 & 46.00 & 45.58 & 19.10 & 8.00 \\
\hline Total & - & - & - & 362.00 \\
\hline
\end{tabular}

$\$ 158,318$. Hence, the postoptimality approach underpredicted the true returns by about $8 \%$. Experience with Texas farms has shown the prediction error to be less than $10 \%$ when increasing machinery capacity by 100 percent or less. However, the error of prediction with the postoptimality approach is problem specific and research is needed to test its accuracy for different agricultural regions.

\section{SUMMARY}

Linear programming has been a popular approach for assisting farm managers with decisions relating to the sizing and selection of field machinery. Many LP models use shadow prices to identify critical machinery that limit productivity. However, shadow prices can give misleading information, since several machines often share resources such as tractors and labor.

A postoptimality algorithm was presented which improves on the shadow price approach. This algorithm improves the prediction of the relative values of each machine. In addition, the procedure can be used to give a detailed summary of the effects of a machinery capacity change on all of the relevant tractor and labor resources. This information on the machinery interactions is useful when machinery changes are being considered.

The algorithm was illustrated with a case study. The case study showed the utility of the postoptimality approach by providing indicators that gave the value of a machine if its capacity was increased by $1 \%$. The machinery values gave a strong indication that the disk was limiting farm productivity. However, shadow prices gave no information to indicate that larger disk capacity was needed. The postoptimality approach also provided detailed information that showed the effect of a machinery change on farm resource utilization. Finally, the postoptimality approach was useful in predicting the value of machinery changes before re-running the timeconsuming LP model. When machinery capacity was increased by no more than $100 \%$, the error of prediction was found to be less than $10 \%$ for Texas farms.

\section{REFERENCES}

Al-Soboh, G., A.K. Srivastava, T.H. Burkhardt and J.D. Kelly. 1986. A mixed-integer linear programming (MILP) machinery selection model for navybean production systems. Transactions of the ASAE 29(1):81-84, 89. 
Bender, D.A., R.M. Peart, J.R. Barrett, D.H. Doster and T.G. Baker. 1984. Optimizing cropping systems using simulation and linear programming. ASAE Paper No. 84-5017. St. Joseph, MI: ASAE.

Brown, W.J. and R.A. Schoney. 1985. Calculating least-cost machinery size for grain farms using electronic spreadsheets and microcomputers. Canadian Journal of Agricultural Economics 33(3):47-65.

Chen, L.H. 1986. Microcomputer model for budgeting and scheduling crop production operations. Transactions of the ASAE 29(4):908-911.

Danok, A.B., B.A. McCarl and T.K. White. 1978. Machinery selection and crop planning on a state farm in Iraq. American Journal of Agricultural Economics 60(3):544-549.

Danok, A.B., B.A. McCarl and T.K. White. 1980. Machinery selection modeling: incorporation of weather variability. American Journal of Agricultural Economics 62(4):700-708.

Doster, D.H., P.R. Robbins, B.A. McCarl and S.D. Parsons. 1980. The Purdue computer crop workshop: Timeliness considerations and other machinery-sizing issues. Purdue Farm Management Report (June), Cooperative Extension Service, Purdue University, W. Lafayette, IN.

Edwards, W. and M. Boehlje. 1980. Machinery selection considering timeliness losses. Transactions of the ASAE 23(4):810-815, 821.

Freund, R.M. 1985. Postoptimal analysis of a linear program under simultaneous changes in matrix coefficients. Mathematical Programming Study 24:1-13.

Hunt, D.R. 1963. Efficient field machinery selection. Agricultural Engineering 44(2):78-79, 88.

Hunt, D.R. 1969. A systems approach to farm machinery selection. Journal of Institute of Agricultural Engineers 24(1):25-27.

Kline, D.E. 1987. Farm-level machinery management using intelligent decision support systems. Ph.D. Diss., Department of Agricultural Engineering, Texas A\&M University, College Station.
Krutz, G.W., R.F. Combs and S.D. Parsons. 1980. Equipment analysis with farm management models. Transactions of the $A S A E$ 23(1):25-28.

McCarl, B.A. 1977. Degeneracy, duality, and shadow prices in linear programming. Canadian Journal of Agricultural Economics 25(1):70-73.

McCarl, B.A. 1982. REPFARM: Design, calculation and interpretation of the linear programming model. Stn. Bull. 385, Agricultural Economics Department, Purdue University, W. Lafayette, IN.

McCarl, B.A., W.V. Chandler, D.H. Doster and P.R. Robbins. 1977. Experiences with farmer oriented linear programming for crop planning. Canadian Journal of Agricultural Economics 25(1):17-30.

McCarl, B.A. and P.Nuthall. 1982. Linear programming for repeated use in the analysis of agricultural systems. Agricultural Systems 8:17-39.

McCarl, B.A. and J. Pheasant. 1983. REPFARM: Documentation of the computer model. Stn. Bull. 409, Agricultural Economics Department, Purdue University, W. Lafayette, IN.

McClendon, R.W., M.E. Wetzstein, D.M. Edwards and L.H. Chen. 1987. Risk efficiency of machinery selection for double cropping via simulation. Transactions of the ASAE 30(5):1259-1265.

Mills, H.D. 1956. Marginal values of matrix games and linear programs. In Linear Inequalities and Related Systems, eds. H.W. Kuhn and A.W. Tucker, 183-193. Princeton, NJ: Princeton University Press.

Murtagh, B.A. and M.A. Saunders. 1983. MINOS 5.0 user's guide. Systems Optimization Laboratory, Department of Operations Research, Stanford, CA.

Whitson, R.E., R.D. Kay, W.A. LePori and E.M. Rister. 1981. Machinery and crop selection with weather risk. Transactions of the ASAE 24(2):288-291, 295. 